\title{
Construction of EH\&S Management System in Pharmaceutical Laboratories in University
}

\author{
Yijia Yuan* \\ School of Pharmaceutical Sciences, Sun Yat-sen University, Guangzhou 510006, China.
}

Abstract: Pharmaceutical science is an experimental subject involving many disciplines. As there are different kinds of risky factors, more and more attentions have been paid to the safety management of pharmaceutical laboratories. The article analyzes the deficiency of current safety management of pharmaceutical laboratories in domestic universities, draws on the EH\&S management model of universities in developed countries and explores measures to construct an EH\&S management system for pharmaceutical laboratories in domestic universities.

Keywords: EH\&S; Pharmaceutical Laboratories; Safety Management

\section{Introduction}

Safety management of pharmaceutical laboratories in colleges and universities involves the management of hazardous chemicals, biological safety, the use and maintenance of equipment with high temperature and high pressure and so on ${ }^{[1]}$. After the Reform and Opening-up, the construction of pharmaceutical laboratories began to develop and at the same time, domestic colleges and universities are paying increasing attention to the health and personal safety of the laboratories staff. However, due to insufficient management measures, there are still many potential safety hazards in domestic pharmaceutical laboratories, which is further worsened by the backward management system.

At present, the laboratories management in developed countries is generally in the charge of EH\&S (Environment, Health and Safety) management office, which is responsible for the safety of construction and management of the school laboratories. EH\&S management system aims at improving the environment and protecting the health and safety of laboratories personnel, which reflects the "people-oriented" management tenet of the colleges and universities in developed countries,.

As an incubator for high-end talents, pharmaceutical laboratories in colleges and universities are supposed to introduce the EH\&S safety management system. The construction of advanced laboratories is important for the development of education, which plays a vital role both practically and theoretically in our process of constructing world-class universities, high level colleges and an innovative country in the long term. Therefore, introducing EH\&S system to pharmaceutical laboratories in domestic universities and colleges is an international and inevitable trend for its safety management.

\section{Problems on safety management of pharmaceutical laboratories}

Pharmaceutical science is an experimental science involving intensive application, high technology and a comprehensive discipline-crossing with biology, chemistry, engineering, material and medicine. Therefore, the safety management of pharmaceutical laboratories in colleges and universities is more complicated. Although currently the responsibility system is applied for safety management, it is mostly carried out in a passive and dependent way, failing to guarantee daily implementation of safety regulations or investigate the potential risks.

\subsection{Loose structure of safety management}

Copyright (C) 2020 Yijia Yuan

doi: 10.18282/1-e.v9i4.1737

This is an open-access article distributed under the terms of the Creative Commons Attribution Non-Commercial License (http://creativecommons.org/licenses/by-nc/4.0/), which permits unrestricted non-commercial use, distribution, and reproduction in any medium, provided the original work is properly cited.

Teaching strategies need to be more in line with the times. When learner-centered college English teaching is widely used and the English level of the Chinese people is constantly improving, this also means that the education of English in our country is constantly developing, the degree of education is gradually increasing, and the talent team is growing. It is a great step forward on the road to the great rejuvenation of the Chinese nation.

\section{References:}

[1] Douglas Reimondo Robertson. Generative Paradox in Learner-Centered College Teaching[J]. Innovative Higher Education Volume 29, Issue 3, 2005.

[2] Abdurrahman KILIC. Learner-centered micro teaching in teacher education [J]. International Journal of Instruction Volume 3, Issue 1, 2010. 
Presently there safety management systems in colleges and universities but is mainly managed by different departments, such as logistics department, security department, equipment department and campus administrative committees. Therefore, specific responsibilities of departments are always unknown or overlapped in practical cases. The superior gives command after accident and the inferior carries it out merely as required without overall planning or prospective design.

\subsection{Difficulty in the implementation of safety system}

Laboratories safety management and construction should follow the "people-oriented" principle. The establishment of safety system in foreign pharmaceutical laboratories often regards the experimental personnel as main part, clearly telling the laboratories personnel "what to do", "how to do" and "how to seek for help in trouble" when they enter laboratories. It also informs them of the risk and their responsibility according to the features of the laboratories. But safety system in domestic pharmaceutical laboratories is often based on rigid regulations, filled with unclear and inefficient instructions like "No", "Stop", "'Don’t" and so on. Therefore, lack of instructive guidance makes it difficult for laboratories staff to fully comprehend and agree with the safety system, which hinders its effective implementation.

\subsection{Lack of safety awareness}

Although the safety personnel and facilities of domestic pharmaceutical laboratories basically meet the management requirements, the awareness of potential risks is still weak due to defects of the management. One typical case is that the regulations are not strictly implemented during the procurement, classification and storage of dangerous goods. In addition, the laboratories personnel is not aware enough of the importance or responsibility of the safety management so they pay less attention and do not carry out the safety measures strictly.

\subsection{Lack of safety education}

The lack of scientific comprehension on laboratories safety leads the safety education to poor content without effective assessment. In colleges and universities safety programs with simple assessments are generally arranged only to freshmen when they are admitted, most of which would forget the specific safety knowledge and escape skills after 3 to 4 years or even longer time. It is the reason why such training and education cannot ensure that students have acquired enough knowledge or skills for safe experimental practice or even their careers after graduation.

\section{The composition and characteristics of EH\&S management system}

Developing at the end of last century, EH\&S is a management mode with a main objective to protect the health and safety of employees in manufacturing enterprises and the public in accordance with the relevant laws and regulations. EH\&S management system was first introduced to chemical industry manufacturing enterprises in western countries in 1985 after a series of disastrous accidents, such as chemical pollution in Italy and gas leakage in India. Since 1990, in order to cultivate more talents, colleges and universities in the United States followed the enterprises to establish departments responsible for EH\&S management and made safety education necessary for laboratory personnel training.

\subsection{Composition of EH\&S management system}

EH\&S management system has rich connotation, which mainly consists of the following 10 parts: (1) power and responsibility of functional departments; (2) risk assessment mechanism; (3) management plans making; (4) daily training of laboratories personnel; (5) safety information communication and exchange mechanism; (6) safety facilities construction; (7) laboratories safety supervision; (8) accidents report and investigation; (9) management processes examination and verification; (10) management improvement. Among them, the power and responsibility of the management department is the core of the system while the risk assessment is the basis of the normal implementation.

\subsection{The characteristics of EH\&S management system}

The management system of EH\&S is a modern management mode, based on prevention and control, full participation, continuous improvement, and featured with self-restraint, self-perfection and self-incentive. As for its function, EH\&S is a forehand analysis and management system for risk. It prevents and controls potential risk by changing management methods and establishing risk preventive mechanisms.

\subsection{Current EH\&S management system in pharmaceutical laboratories}

Unlike developed countries, generally domestic universities and colleges lack reliable laws, regulations or standard operation procedures on laboratories safety. Additionally, laboratories safety is in the charge of several independent departments without effective coordination so it is hard to form a standardized management system. As for the domestic construction of $\mathrm{EH} \& \mathrm{~S}$ management system, it started late and is still in searching and investigation phase. Currently, China's higher education is challenged by the marketization of society. Under the dual pressures of the rapid college expansion and intensive society demand of achievement, the higher education has ignored problems on environment, health and safety. Because of the characteristic of pharmaceutical science research, some laboratories in colleges and universities are far more dangerous than those in enterprises.

\section{Case analysis: EH\&S in University of California-Berkeley}

University of California-Berkeley (UCB) has established a comprehensive EH\&S system and even an exclusive website. The website is rich in content, with plentiful information displaying the management mode and the organization structure of EH\&S system. The website has 3 types of navigation directory: (1) items of business, such as "about us", contact information and so on. "About us" column shows the service tenet of the school EH\&S management office: "we are committed to provide the campus with guidance and services for health, safety and environmental protection management." These items facilitate teachers 
and students' access to more information; (2) items of disciplinary projects, such as biological safety, chemical safety, controlled chemicals, radiological safety and so on; (3) items of guidelines, including three links placed on most prominent place on home page: guideline for emergency, guideline for anonymous report on safety accident and guideline for treatment of wasted agents. Based on the data collected, we can summarize three features of the EH \&S of UCB.

\subsection{Regulations construction}

The management and construction of laboratories safety require not only self-discipline of students and teachers but also supervision of laws and regulations. Regulations of EH\&S management system relies on its handbook, which refers two documents: Occupational Safety and Health Act (United States) chapter 8, about occupational exposures to hazardous chemicals in laboratories and Laboratories Safety Guidance issued by The Occupational Safety and Health Administration.

\subsection{Complete system framework}

Most EH\&S management system of American universities is an individual department with full-time personnel. The EH\&S management office is usually led by a chief executive and includes 6 parallel functional teams, which are separately responsible for: (1) management, technical and professional support, security guarantee for administrative and financial resources information systems; as well as responsible for the compliance of corporate operations within the school management and risk control; (2) protection and improvement of the campus environment and hazardous product management; (3) fire protection and security for teachers, students and campus property; (4) safety counseling; training in campus, health and safety hazard assessment for laboratories staff; (5) campus emergency management; (6) monitoring the safe use of ionizing radiation within the campus.

In addition, air quality, food and drinking water security are also included in the EH\&S management system by UCB.

\subsection{Routinely security training}

It is of great significance for laboratories to offer security training to staff. For example, UCB provides different staffs with different training courses annually, including biological security, laboratories dangerous facilities safety, high pressure equipment safety, radiation safety personal emergency treatment and other different training courses. Most EH\&S training courses adopt a short-term cycling teaching pattern. Small class teaching or online teaching is also available for the convenience of personal study. There is a strict examination at end of the course to assure the outcome of training.

\section{Construction of the EH\&S management system in pharmaceutical laboratories}

The safety management of laboratories is an important reflection of teaching level, scientific research level and management level of a university. It is not only an objective need to construct the discipline of pharmaceutical science, but also a requirement to build a world-class comprehensive university.

\subsection{Structure and system construction}

Reasonable top level design helps to improve the safety management of pharmaceutical laboratories. Pharmaceutical departments are supposed to set up a special responsibility office for the management under the guidance of the school committee. Members should be composed of the vice presidents of security office, teachers' representatives and students' representatives. The PI group is directly responsible for management and supervision of laboratories safety. Generally, main responsibility of the laboratories safety management office is: (1) to formulate college EH\&S management system and carry out daily supervision; (2) to be responsible for the maintenance of laboratories safety facilities and the protection of laboratories environment, and to monitor the use of funds for laboratories safety construction; (3) to regularly organize training and fire drill; (4) to conduct regular health inspection; (5) to handle laboratories safety accident report.

\subsection{Risk assessment and preventive measures}

Risk assessment is a quantitative evaluation of operation, facility and reagent which may cause harm to laboratories personnel. It is the basis of laboratories safety management system. Correct and reasonable risk identification and assessment can help to develop targeted measures to eliminate the risk. Generally, a common risk assessment process consists of: (1) identifying potential risks; (2) determining possible damage the risk will cause to laboratories personnel; (3) proposing preventive measures; (4) implementing the measures and regularly monitoring; (5) formulating emergency plan in case of further risks.

\subsection{Accident report and rectification}

Safety accidents in pharmaceutical laboratories should be reported to school laboratories safety management committee and the relevant functional departments in accordance with the reporting procedures after occurrence. Statistical analysis of the accident should be carried out as reference for further plan making on targeted improvement measures.

5.4 Safety education and awareness training

Everybody only lives once, so the first consideration of all universities should be the safety of teachers and students. EH\&S management system in foreign universities emphasizes the protection of human health and the environment in the laboratories, which should be referred by the domestic pharmaceutical laboratories. Although the current colleges and universities are required to conduct safety trainings and fire drills, it is only limitedly implemented during the entrance of freshmen, which is insufficient and ineffective. Since the particularity and complexity of pharmaceutical science, a variety of safety trainings forms should be taken, such as handbooks or textbooks, online courses, centralized teaching and other combinational forms. At the same time, regular training should also target mentors and senior students.

\section{Conclusion}

The establishment of EH\&S management system can provide maximum support for the safety operation of pharmaceutical 


\title{
A Comparative Study of Police Government Microblog and Government Tik Tok
}

\author{
Ainan $\mathrm{Zhu}^{1}$, Xia $\mathbf{L i}^{2}$ \\ 1People's Public Security University of China, Beijing 100038, China. \\ 2School of foreign languages, Chongqing Normal University, Chongqing 401331, China.
}

Abstract: Based on "government micro-blog" and "government tiktok" of Chinese Police Online, this paper collects data with the help of Octopus Collector and Python, then studies the status quo of Chinese police on-line through two new government media platforms: Weibo and Weibo public security organs to use new media to carry out government propaganda and public opinion guidance and control work.

Keywords: Public Opinion of Public Security; Government Tiktok; Government Micro-Blog;

\section{Introduction:}

In recent years, as important new media of government affairs, government micro-blog and government tiktok can respond to public opinion concerns in a timely and effective way, and effectively guide public opinion, playing a very important role in social security governance. In order to give full play to the role of new government affairs media in guiding and controlling public opinions on criminal networks, it is necessary for us to conduct in-depth analysis of new government affairs media and make targeted optimization and improvement.

\section{Research design and research methods}

In order to study the similarities and differences between tiktok and weibo in government affairs communication, public opinion management and control, this paper takes tiktok and weibo in government affairs online of Chinese police as the research objects, to collect data (basic data is shown in Table 1) and do quantitative analysis on Chinese police online government tiktok and government micro-blog from November 1 to 30, 2020 by means of octopus data collector and Python tools ${ }^{[1]}$.Then, a comparative study is made between Chinese police online government micro-blog and tiktok, discussing the characteristics and differences of information dissemination. For the research methods, I use statistical analysis method and text analysis method.

Table 1 Basic data of Chinese police online government micro-blog and government tiktok

\begin{tabular}{|c|c|c|c|c|c|}
\hline New media & Name & $\begin{array}{c}\text { Number of fans } \\
\text { (ten thousand) }\end{array}$ & $\begin{array}{c}\text { Quantity of data } \\
\text { collected (pieces) }\end{array}$ & $\begin{array}{c}\text { Remarks of Government } \\
\text { Media }\end{array}$ & $\begin{array}{c}\text { Data collection } \\
\text { time }\end{array}$ \\
\hline
\end{tabular}

Copyright (C) 2020 Ainan Zhu et al.

doi: $10.18282 / 1-e . v 9 i 4.1738$

This is an open-access article distributed under the terms of the Creative Commons Attribution Non-Commercial License (http://creativecommons.org/licenses/by-nc/4.0/), which permits unrestricted non-commercial use, distribution, and reproduction in any medium, provided the original work is properly cited.

laboratories in colleges and universities. It should become a prerequisite part of the safety construction in pharmaceutical laboratories because it can guarantee the normal teaching and research in colleges and universities. As part of the safety management system of pharmaceutical laboratories, the importance and development direction of safety management should be clearly comprehended so that in future, great effort could be made to strengthen top-level design, cultivate high-end pharmaceutical talents and promote the development of pharmaceutical sciences.

\section{References}

[1] Tian Chenning, Li Hongxia, Tian Shuicheng, Tian Fangyuan. (2020). Risk Assessment of Safety Management Audit Based on Fuzzy TOPSIS Method[J]. Mathematical Problems in Engineering, 2020, 1-11.

[2] Wang Houmiao. (2019). Analysis of University Laboratory Safety Status and Management Strategy[J]. The Science Education Article Collects, 2019(10), 26-27.

[3] Su Ruxiang, Yang Ruixia. (2019). Exploration on the Safety Management Mode of University Laboratories[J]. Chemical Enterprise Management, 2019; (12), 93-97.

[4] M.S. Keckler, K. Anderson, S. McAllister, J.K. Rasheed, J. Noble-Wang. (2019) Development and Implementation of Evidencebased Laboratory Safety Management Tools for A Public Health Laboratory[J]. Safety Science, 2019; (117), $205-216$. 